\title{
Pembentukan Identitas Diri Para Pelaku Cover Dance K-Pop di Jakarta
}

\author{
Dwi Sabrina, Lusia Savitri Setyo Utami \\ Dwi.9151600.63@stu.untar.ac.id,lusias@fikom.untar.ac.id
}

Fakultas Ilmu Komunikasi Universitas Tarumanagara

\begin{abstract}
No doubt the development of popular culture is very fast in the world, especially the K-Pop industry. Due to rapid development of K-Pop and more fans, innovations have begun to emerge in showing the love of fans towards K-Pop. One of them is K-Pop cover dance activities. This study discusses "The Formation of the Identity of K-Pop Cover Dance Performers in Jakarta" and uses observation and interview data collection methods to find out more about how the formation of K-Pop cover actors' self-identity formation. The theory used is their dramatism on the front stage and also the backstage. In this study the authors can see that each individual communicates themselves in different ways and not all cover dance performers perform their front stage roles up to their backstage life. The formation of the identity of the cover dance actors can change to follow the environment where they are and with whom they communicate. However, not a few also feel that his life as a cover dance on stage imitates and becomes someone else's figure carried to their daily from various aspects such as family, experience and also the community.
\end{abstract}

Keywords: dramatism, pop culture, self identity.

\begin{abstract}
Abstrak
Tidak dipungkiri perkembangan budaya populer sangat pesat di dunia terutama K-Pop. Akibat perkembangan K-Pop yang pesat dan penggemarnya yang semakin banyak, mulai bermunculan inovasi dalam menunjukkan kecintaan dari penggemar terhadap K-Pop. Salah satunya adalah kegiatan cover dance K-Pop. Penelitian ini membahas tentang "Pembentukan Identitas Diri Para Pelaku Cover Dance K-Pop di Jakarta" dengan menggunakan teori dramatisme mereka pada front stage dan juga back stage. Dalam penelitian ini penulis dapat melihat bahwa setiap individu mengkomunikasikan diri mereka dengan cara yang berbedabeda dan tidak semua pelaku cover dance melakukan peran front stage mereka hingga ke kehidupan backstage mereka. Peneliti menggunakan metode pengumpulan data observasi dan wawancara untuk mengetahui lebih dalam mengenai bagaimana pembentukan identitas diri para pelaku cover dance K-Pop. Pembentukan identitas diri para pelaku cover dance dapat berubah mengikuti lingkungan dimana mereka berada dan dengan siapa mereka berkomunikasi. Namun, tidak sedikit juga yang merasa bahwa kehidupannya sebagai seorang cover dance di atas panggung yang meniru dan menjadi sosok orang lain terbawa hingga ke kehidupan sehari-hari mereka dari berbagai macam aspek seperti keluarga, pengalaman dan juga komunitas.
\end{abstract}

Kata Kunci: budaya populer, dramatisme, identitas diri.

\section{Pendahuluan}

Saat ini budaya populer dari barat tidak lagi menjadi satu-satunya budaya populer yang banyak dikonsumsi oleh masyarakat, khususnya di Indonesia dan berbagai wilayah Asia lainnya. Namun, bukan berarti musik dan film Hollywood tidak 
berpengaruh lagi, hanya saja mereka tidak lagi yang menjadi satu-satunya pusat budaya populer di dunia.

Budaya populer dibuat oleh masyarakat, tidak dihasilkan oleh industri budaya, yang dapat dilakukan oleh industri-industri budaya hanyalah menghasilkan repertoar teks atau sumberdaya budaya bagi pelbagai lapisan masyarakat untuk digunakan atau ditolak dalam proses yang sedang berlanjut dalam menghasilkan budaya popular mereka (Fiske, 2011).

Sebagian besar perhatian dunia, terutama di kalangan remaja, tengah mengarah kepada budaya Korea Selatan. Hal ini terjadi karena adanya invasi besar-besaran pada bidang budaya dan juga seni Korea Selatan atau terkenal juga dengan sebutan Hallyu Wave. Korea Selatan sangat sukses dalam menyebarkan budaya mereka seperti, drama, musik, makanan, fashion, hingga bahasa. Hallyu Wave merupakan bentuk dari meningkatnya minat publik pada kesenian pop dan budaya tradisional Korea di Asia, Eropa, Timur Tengah dan Benua Amerika (Rachmah, 2017).

Dalam penelitian ini, peneliti ingin mengetahui pembentukan identitas diri para pelaku cover dance khususnya di Jakarta. Peneliti ingin mengetahui implikasi identitas diri yang dimunculkan dalam kehidupan sehari-hari para pelaku cover dance di Jakarta.

Beberapa teori yang mendasari penelitian penulis adalah teori budaya populer yang menjelaskan budaya populer yang diproduksi dan didistribusikan pada masyarakat tidak lagi mengenal batas-batas geografisnya. Perkembangan media massa dan teknologi komunikasi serta informasi mempercepat arus distribusi dan konsumsi budaya populer local ke belahan dunia yang tidak mungkin tersekat lagi (borderless). Globalisasi industri media telah berlangsung melalui proses akumulasi atau sedimentasi dari lapisan-lapisan atau ruang-ruang yang meledak dalam dunia panggung media, menjadi bagian penting dalam proses industri media yang kompleks seperti televisi (Ida, 2017).

Teori selanjutnya adalah dramatisme yang menjelaskan mencoba memahami tindakan kehidupan manusia sebagai drama. Sesuai dengan namanya, dramatisme mengkonseptualisasikan kehidupan sebagai drama, menempatkan suatu fokus kritik pada adegan yang diperlihatkan oleh berbagai pemain. Di dalam dramatisme juga terdapat pentad, sebuah peristiwa selalu dapat dianalisis dengan menggunakan dramatistic pentad (pentad yang bersifat dramatis). Pentad disini terkait dengan kelompok yang terdiri atas lima unsur. Kelima unsur ini digunakan untuk menganalisis berbagai tindakan dengan cara yang paling efisien.

Teori yang terakhir peneliti gunakan adalah teori identitas diri dari Erikson (1989) menjelaskan identitas sebagai perasaan subjektif tentang diri yang konsisten dan berkembang dari waktu ke waktu. Dalam berbagai tempat dan berbagai situasi sosial, seseorang masih memiliki perasaan menjadi orang yang sama. Sehingga, orang lain yang menyadari kontinuitas karakter individu tersebut dapat merespon dengan tepat. Sehingga, identitas bagi individu dan orang lain mampu memastikan perasaan subjektif tersebut.

Faktor-faktor yang mempengaruhi identitas diri manusia terdiri dari beberapa hal yang pertama adalah orang tua ketika orang tua menyediakan dukungan emosional dan kebebasan bagi anak untuk menjelajahi lingkungannya, maka anak akan berkembang dengan memiliki pemahaman yang sehat mengenai siapa dirinya. 
Faktor yang kedua adalah interaksi dengan teman sebaya, yaitu melalui interaksi dengan teman sebaya yang beragam, perolehan remaja mengenai ide dan nilai juga akan bertambah. Adanya dukungan secara emosi yang diperoleh dari teman dekat akan membuat mereka saling membantu.

Faktor yang ketiga adalah komunitas, yaitu komunitas yang menawarkan kesempatan yang luas dan beragam dalam hal pencarian yang dilakukan oleh seseorang juga mendukung pembentukan identitas. Faktor keempat adalah kebudayaan yaitu, budaya memiliki pengaruh besar dalam perkembangan identitas, dimana budaya dapat membentuk adanya self continuity disamping perubahan diri yang terjadi (Suciati, 2017).

\section{Metode Penelitian}

Dalam penelitian ini penulis berupaya mengumpulkan data dan informasi yang dibutuhkan untuk melengkapi penelitiannya dengan menggunakan cara wawancara mendalam bersama sejumlah narasumber yang terkait tertentu yang berhubungan dengan penelitian penulis dan penelusuran terhadap data-data sekunder melalui bukubuku serta sumber online.

Metode yang peneliti gunakan adalah pendekatan penelitian yang digunakan penulis dalam meneliti pembentukan identitas diri pada pelaku cover dance K-pop di Jakarta adalah pendekatan kualitatif. Metode kualitatif pada awalnya muncul karena terjadi perubahan paradigma dalam memandang suatu realitas atau fenomena atau gejala. Metode penelitian kualitatif adalah metode penelitian ilmu-ilmu sosial yang mengumpulkan dan menganalisis data berupa kata-kata dan perbuatan manusia (Afrizal, 2016).

Selain itu, teknik analisis data dalam metode penelitian penulis ini adalah deskriptif-kualitatif dan juga menggunakan model Miles dan Huberman. Metode deskriptif-kualitatif mencari teori, bukan menguji teori; hypothesis-generating, bukan hypothesis-testing; dan heuristic, bukan verifikasi. Menurut Miles dan Huberman ada tiga jenis kegiatan dalam analisis data adalah reduksi data, model data dan juga penarikan atau verifikasi kesimpulan. Teknik keabsahan data yang digunakan dalam penelitian ini adalah triangulasi data. Triangulasi data adalah teknik pemeriksaan keabsahan data yang memanfaatkan sesuatu yang lain.

\section{Hasil Penemuan dan Diskusi}

Kegiatan K-Pop cover dance biasanya terinspirasi dari kecintaan dan ketertarikan para penggemar pada koreografi dan musik idola K-Pop. Seakan tak cukup hanya dengan menikmati penampilan artis-artis $K$-Pop favorit di atas panggung, banyak penggemar kemudian terinspirasi untuk meniru koreografi yang disuguhkan oleh sang idola (Elma, 2018).

Korean Wave banyak digandrungi oleh masyarakat baik anak-anak maupun dewasa. Bahkan Indonesia sudah beberapa kali kedatangan artis Korea seperti boyband maupun girlband. Tak heran jika Korean Wave ini yang sangat populer di Tanah Air dan banyak yang menjadi penggemar budaya Korea. Dengan genre musik K-Pop ini yang memadukan antara musik dan dance membuat para penggemarnya untuk membuat sebuah komunitas cover dance Korea (Elma, 2018). 
Berdasarkan hasil wawancara yang peneliti lakukan dengan ketiga pelaku cover dance K-Pop di Jakarta mengenai pembentukan identitas diri mereka, penulis dapat melihat bahwa mereka tentunya memiliki standard ketika mereka berada diatas panggung. Para pelaku cover dance ini diharuskan untuk bisa semaksimal mungkin memiliki kesamaan dari segi manapun dengan idol yang mereka cover. Baik dari segi penampilan, kostum ketika tampil, make up hingga ekspresi dan mimik ketika mereka perform harus semirip mungkin dengan para idol tersebut.

Dari hasil penelitian yang peneliti lakukan, diantara ketiga narasumber terdapat dua narasumber yang terbawa pada kehidupan sehari-hari identitas seorang idol yang mereka cover, bahkan kegiatan cover dance tersebut menjadi salah satu pembentukan identitas diri mereka hingga saat ini. Namun, salah satu narasumber memaparkan bahwa dirinya sama sekali tidak terpapar hingga ke backstage. Narasumber yang tidak terpengaruh hingga ke kehidupan back stagenya ini memaparkan bahwa terjun ke dunia cover dance hanya untuk mencari dan menambah teman dan dia tidak menjadikan kegiatan cover dance ini sebagai sebuah pekerjaan.

\section{Dramatisme pada pelaku cover dance K-Pop di Jakarta}

Dalam dramatisme para pelaku cover dance ini peneliti mendapatkan informasi bahwa ketiga narasumber tentunya ketika berada di front stage memiliki motif yang sama yaitu merepresentasikan diri mereka sebagai seorang idol yang mereka cover, dengan berbagai macam cara mereka lakukan. Namun, dibalik itu semua peneliti menemukan berbagai macam motif ketika sudah berada di fase backstage.

Perilaku pada front stage seseorang dibatasi dengan konsep-konsep drama untuk membuat drama menjadi berhasil. Sedangkan back stage adalah keadaan dimana kita berada di belakang panggung perilaku atau watak kita yang sesungguhnya, dengan kondisi tidak ada penonton. Dengan demikian kita dapat berperilaku bebas tanpa memperdulikan konsep-konsep drama yang mengatur peran kita (Suciari, 2017).

Narasumber pertama yaitu Priscilla setelah peneliti melakukan wawancara yang mendalam dengan dirinya peneliti mengetahui bahwa ketika di fase backstage, Priscilla tidak lagi menganggap bahwa cover dance merupakan hal yang paling utama dalam kehidupan sehari-harinya. Mengingat Priscilla tidak menjadikan cover dance sebagai pekerjaan yang tetap, melainkan hanya sarana untuk menyalurkan kegemarannya.

Narasumber kedua yaitu Jungdidi diantara ketiga narasumber yang diwawancarai oleh peneliti secara mendalam, Jungdidi merupakan informan yang kehidupannya sangat dipengaruhi. Bahkan hingga pada fase backstage Jungdidi merasa tidak ada perbedaan, karena pada fase backstage Jungdidi tetap ingin merepresentasikan dirinya sebagai seorang penggemar dari Kang Daniel, berbeda ketika di front stage dia merepresentasikan dirinya sebagai seorang Kang Daniel. Informan kedua ini ketika berada di backstage tetap ingin dikenal sebagai penggemar dari Kang Daniel.

Narasumber ketiga yaitu Patrisca dari hasil wawancara yang mendalam peneliti dapat menyimpulkan bahwa Patrisca tetap terpapar akibat dari pekerjaannya sebagai seorang cover dance, namun yang Patrisca serap hanyalah dari segi rambut sang idol tidak lebih dan tidak kurang. Patrisca memaparkan bahwa kehidupannya di front stage sangat berbeda dengan kehidupannya di backstage. 


\section{Pembentukan identitas diri para pelaku cover dance K-Pop di Jakarta}

Pada pembentukan identitas diri para pelaku cover dance dalam penelitian yang peneliti telah lakukan, peneliti menemukan bahwa identitas para narasumber yang diwawancarai merasa bahwa identitas diri mereka sedikit banyak berubah. Seperti Priscilla yang merasa identitas dirinya berubah dan dia juga menjadi lebih mudah berinteraksi dengan yang lain setelah mengikuti kegiatan cover dance ini dan merasa lebih percaya diri dalam berpakaian (Heryanto, 2019).

Narasumber kedua yaitu Patrisca, menurut peneliti pada awalnya Patrisca masih ragu dan juga bingung dikarenakan dengan dirinya yang tomboy namun setelah bergabung dan mulai mengikuti cover dance Patrisca justru lebih percaya diri dengan penampilannya dan merasa sangat nyaman dengan dirinya yang seperti itu.

Sedangkan salah satu narasumber yaitu Jungdidi memaparkan bahwa identitas dirinya sangat berubah setelah mengenal K-Pop dan memasuki dunia cover dance. Sebelum mengenal dunia cover dance Jungdidi sama sekali tidak memperdulikan penampilannya layaknya laki-laki pada umumnya. Namun, setelah mengenal dunia cover dance Jungdidi menjadi sangat memperhatikan penampilannya hingga dia harus menyisihkan sebagian gajinya untuk keperluan seperti skincare, makeup dan juga gym.

Dari hasil wawancara peneliti dengan ketiga narasumber tersebut peneliti dapat menyimpulkan bahwa identitas diri mereka sangat terpengaruh oleh lingkungan mereka dan situasi yang mereka hadapi. Mereka dapat memilih dan menentukan bagaimana mereka berpenampilan saat di front stage dan juga saat di backstage.

Peneliti juga dapat menyimpulkan bahwa identitas diri seseorang sangat terpengaruh oleh tempat dan lingkungan mereka tumbuh dan berkembang, hal-hal tersebut yang membentuk identitas dan kepribadian mereka sendiri. Setiap individu dapat menentukan seperti apa dan ciri khas seperti apa yang ingin mereka tunjukan di depan publik.

Identitas diri yang terdiri dari setting, kostum, kata-kata, non verbal, dan sebagainya. Hal ini tidak lain adalah untuk memuluskan jalan untuk mencapai tujuannya, dengan kata lain ketiga narasumber tersebut memiliki tujuan yang sama dalam melakukan dan menekuni kegiatan cover dance ini yaitu mereka ingin mempresentasikan diri mereka sebagai idol yang mereka suka.

Jika peneliti tinjau melalui teori Identitas Diri yang mengatakan bahwa identitas diri dibangun melalui peran-peran yang dimunculkan saat kita berkomunikasi. Dalam upaya mendefinisikan sebuah situasi, seseorang akan melewati proses yang terdiri dari dua bagian. Pertama, mendapatkan informasi dari orang-orang yang berada dalam situasi tersebut. Kedua, memberikan informasi tentang dirinya sendiri.

Apabila dikaitkan dengan kehidupan para pelaku cover dance ini mereka tentunya melihat keadaan di dalam komunitas dan disekitar mereka berada, tentunya di sekitar mereka banyak sekali individu-individu yang mempresentasikan diri mereka dengan beragam cara yang berbeda. Setelah itu keputusan untuk menjadi seperti apa terletak pada masing-masing individu.

Fenomena kegiatan cover dance ini memiliki kesamaan dengan fenomena cosplayer dari Jepang, cosplay adalah istilah bahasa Inggris buatan Jepang yang berasal dari gabungan kata "costume" (kostum) dan "play" (bermain). Mirip dengan kegiatan cover dance, cosplay merupakan kegiatan yang menirukan pakaian beserta aksesoris dan rias wajah. Pada identitas diri dari fenomena cover dance dan juga cosplayer ini para pelaku sama-sama memiliki keunikannya masing-masing dalam diri 
mereka. Ketika mereka memerankan sosok orang lain di depan umum, mereka samasama harus menunjukkan identitas diri mereka sebagai orang lain (dalam Sabka, Setyanto, \& Winduwati, 2018).

Oleh karena itu kegiatan cover dance ini memiliki kesamaan dengan kegiatan crossdresser cosplay yaitu mereka sama-sama merepresentasikan diri mereka sebagai orang lain ketika berada di depan masyarakat dan juga mereka sama-sama harus totalitas dengan penampilan mereka ketika berada di atas panggung yang dapat mempengaruhi identitas diri mereka sedikit demi sedikit.

\section{Dramatisme sebagai pendukung pembentukan identitas diri}

Dramatisme menjadi pendukung pembentukan identitas diri karena para pelaku cover dance yang menampilkan sisi front stage secara terus menerus dan berulang di hadapan masyarakat luas tentunya hal tersebut dapat menjadi sebuah kebiasaan yang dapat mempengaruhi identitas diri mereka. Ketika seseorang pelaku cover dance terus menerus berpakaian dan bergaya ala seorang idola yang mereka cover dalam jangka waktu yang lama, maka secara tidak langsung hal tersebut dapat mempengaruhi identitas diri mereka sendiri, identitas diri mereka dapat berubah mengikuti sosok idola yang mereka cover tersebut.

Hasil dari wawancara dengan narasumber, peneliti mengetahui bahwa perkembangan dari budaya populer (Hallyu Wave) juga menjadi salah satu penyebab para pelaku cover dance dapat terjun ke dunia cover dance ini, dengan mereka mengkonsumsi banyak konten-konten seperti sering menonton music video, variety show dan juga reality show membuat mereka semakin mencintai Hallyu Wave dan hal tersebut yang membuat mereka ingin menjadi seperti para idola tersebut.

\section{Simpulan}

Kesimpulan yang dapat penulis paparkan dari hasil penelitian ini adalah bahwa para pelaku cover dance ini mementaskan diri mereka layaknya seperti seorang idola ketika berada di depan panggung (front stage). Sedangkan ketika berada di belakang panggung (backstage) mereka kembali kepada identitas diri mereka meskipun juga ada yang terpapar dari idola yang mereka cover dan terbawa dalam kehidupan sehari-hari. Peneliti juga dapat menyimpulkan bahwa identitas diri seseorang sangat terpengaruh oleh tempat dan lingkungan mereka tumbuh dan berkembang, hal-hal tersebut yang membentuk identitas dan kepribadian mereka sendiri. Setiap individu dapat menentukan seperti apa dan ciri khas seperti apa yang ingin mereka tunjukan di depan publik. Oleh karena itu, dari hasil penelitian ini peneliti merekomendasikan agar para pelaku cover dance dapat mengambil nilai-nilai yang positif dan dapat memilah mana yang dapat diadaptasi dari kegiatan cover dance tersebut.

\section{Ucapan Terima Kasih}

Dalam penelitian ini penulis ingin mengucapkan banyak terimakasih kepada kedua orang tua penulis yang menjadi penyemangat penulis dalam penelitian ini, untuk Jungdidi, Patrisca dan juga Priscilla yang telah bersedia menjadi narasumber dalam penelitian ini dan kepada teman-teman seperjuangan penulis yaitu Deka Marcella, Dwi Devita, Feren Jachinta, Meydhita dan Nisrina yang juga menyemangati penulis untuk penelitian ini. 
Dwi Sabrina, Lusia Savitri Setyo Utami: Pembentukan Identitas Diri Para Pelaku Cover Dance K-Pop di Jakarta

\section{Daftar Pustaka}

Afrizal. (2017). Metode Penelitian Kualitatif. Jakarta: Pustaka Setia.

Erikson, Erik H. (1989). Identitas dan Siklus Hidup Manusia Bunga Rampai I . Jakarta: Gramedia.

Heryanto, Ariel. (2019). Identitas dan Kenikmatan Politik Budaya Luar Indonesia. Jakarta: Gramedia

Fiske, John. (2011). Memahami Budaya Populer. Yogyakarta: Jalasutra.

Sabka, Fasa. Setyanto, Yugih, \& Winduwati, Septia. (2018): Pengungkapan Identitas Diri Melalui Komunikasi Non Verbal Artifaktual Pada Komunitas Crossdress Cosplay Jepang. Jurnal Komunikasi, 2 (2), 345-351. Desember 2018. Terarsip di : https://journal.untar.ac.id/index.php/koneksi/article/view/3905/2291

Suciati. (2017). Komunikasi Dalam Multi Perspektif. Yogyakarta : Buku Literal 